\title{
Custo de produção e lucratividade da cultura do amendoim no município de Jaboticabal, São Paulo
}

\author{
Rafael Marani Barbosa', Bruno Fernandes Modesto Homem², Maria Aparecida Anselmo Tarsitano ${ }^{3}$ \\ http://dx.doi.org/10.1590/0034-737X201461040005
}

\section{RESUMO}

O Estado de São Paulo é o maior produtor de amendoim do Brasil e a produção concentra-se na região de Ribeirão Preto, onde o cultivo é realizado em áreas arrendadas, em esquemas de sucessão e rotação, principalmente, para reforma de canaviais. Nesse caso, a rotação com amendoim durante a entressafra é escolha viável, pois além de poder ser rentável, as terras que ficariam ociosas mantêm a sua produtividade. Por esta razão, o objetivo deste trabalho foi estimar e analisar o custo de produção e a rentabilidade do amendoim cv. Runner IAC 886, em áreas de reforma de canaviais, na região de Jaboticabal, São Paulo, para a safra 2010/2011. Utilizou-se a metodologia do Custo Operacional Total e calcularam-se os indicadores de lucratividade: receita bruta, lucro operacional e índice de lucratividade, considerando-se três níveis de preços recebidos pelos produtores. O custo operacional total da produção de amendoim foi de $\mathrm{R} \$ 3.665,21 \mathrm{ha}^{-1}$, devido, principalmente, às despesas com colheita e arrendamento da terra. Os índices econômicos foram satisfatórios somente para o nível de preço representado pelo valor médio obtido nos últimos anos. Em relação ao Preço Mínimo de Garantia, os resultados não apresentaram lucro.

Palavras-chave: Arachis hypogaea L., reforma de canavial, rentabilidade, rotação.

\section{ABSTRACT}

\section{Production costs and profitability of peanut in Jaboticabal, São Paulo}

The region of Ribeirão Preto in the State of São Paulo is the largest peanut producer in Brazil, where the crop is cultivated in leased areas in succession and rotation systems, mainly for renewal of sugarcane plantations. In this case, the rotation with peanut during the fallow period is a viable alternatve because is profitable and keep the areas productive. Thus, the aim of this study was to estimate and analyze the production cosst and profitability of peanut cv. Runner IAC 886 in the renewal of sugarcane areas in Jaboticabal, São Paulo, for the crop year 2010/2011. The methodology of Total Operating Cost was applied along with the profitability indicators: gross revenue, operating income and profitability index, considering three levels of prices received by producers. The total operating cost of peanut production was R \$3,665.21 ha-1, mainly due to expenditure on crop and land lease. Economic indices were satisfactory only for the price level represented by the mean value obtained in recent years. Results failed to show profit for the Minimum Price Guarantee.

Key words: Arachis hypogaea L., profitability, sugarcane renewal, rotation.

\footnotetext{
Recebido para publicação em 14/12/2012 e aprovado em 06/09/2013.

${ }^{1}$ Engenheiro-Agrônomo, Doutor. Departamento de Produção Vegetal, Universidade Estadual Paulista "Júlio de Mesquita Filho", Campus de Jaboticabal, Via de Acesso Professor Paulo Donato Castellane s/n, 14884-900, Jaboticabal, São Paulo, Brasil. rmarani@gmail.com (autor para correspondência).

2 Engenheiro-Agrônomo, Mestre. Departamento de Produção Vegetal, Universidade Estadual Paulista "Júlio de Mesquita Filho", Campus de Jaboticabal, Via de Acesso Professor Paulo Donato Castellane s/n, 14884-900, Jaboticabal, São Paulo, Brasil. bruno.homem@yahoo.com.br

${ }^{3}$ Engenheira-Agrônoma, Doutora. Departamento de Fitotecnia, Tecnologia de Alimentos e Sócio Economia, Universidade do Estado de São Paulo "Júlio de Mesquita Filho", Campus de Ilha Solteira, Avenida Brasil, 56, Centro,15385-000, Ilha Solteira, São Paulo, Brasil. maat@agr.feis.unesp.br
} 


\section{INTRODUÇÃO}

$\mathrm{O}$ amendoim é considerado a segunda leguminosa em importância no mundo. Cultivado, principalmente, como importante fonte de proteína vegetal e de óleo, seus grãos podem apresentar até 50\% de lipídeos (Nakagawa \& Rosolem, 2011). A China é o principal país produtor de amendoim, representando $43 \%$ da produção mundial, estimada em 34,7 milhões de toneladas, em 2010 (Agrianual, 2011).

A área total nacional de amendoim (considerando-se as duas safras) atingiu $93,9 \mathrm{mil} \mathrm{ha,} \mathrm{com} 75,9 \mathrm{mil} \mathrm{ha}(80,8 \%)$ cultivados em São Paulo; a produção alcançou 294,7 mil toneladas, $23,1 \%$ superior à colhida na safra anterior, tendo a produtividade atingido $3.137 \mathrm{~kg} \mathrm{ha}^{-1}$. A região sudeste foi a maior produtora de amendoim com 271,3 mil toneladas, 92,0\% da produção nacional, com destaque para São Paulo com $97,0 \%$ da produção total da região sudeste e 89,0\% da produção nacional (Conab, 2012).

Nas últimas safras, a produção paulista de amendoim tem apresentado variações, atingindo em média 224 mil toneladas, em 2009, maior valor nos últimos seis anos, em quase 80 mil ha. Em 2010, este valor caiu para 186,3 mil toneladas, em $60 \mathrm{mil}$ ha (IEA, 2011b). Tradicionalmente, o amendoim paulista é produzido em duas regiões: na Alta Mogiana (região de Ribeirão Preto e Jaboticabal), onde a cultura encontra espaço na renovação dos canaviais, com produção da safra das águas, e na Alta Paulista (região de Marília e Tupã), onde a renovação de pastagens e canaviais torna disponíveis as áreas para produção de duas safras, a principal (safra das águas) e a safrinha (ou safra da seca) (Martins, 2010).

Na região de Jaboticabal, a produção, em 2010, atingiu patamar de 32,5 mil t, em área cultivada de 8.460 ha (IEA, 2011b). Essa produção deu-se quase, na totalidade, em áreas de renovação de canaviais, em que, a cada ano são renovados de 10 a $15 \%$ dos canaviais da região. As áreas de renovação são cultivadas, principalmente, por arrendatários de terras (grandes proprietários rurais arrendam suas terras a terceiros para o cultivo do amendoim, na entressafra da cana-de-açúcar), sendo o cultivo e a colheita mecanizados.

A utilização da rotação de culturas com leguminosas, na cultura da cana-de-açúcar, é recomendada quando se reforma o canavial. Essa prática não interfere na brotação da cana. Seu custo é relativamente baixo e a rotação promove aumentos significativos nas produções de cana, em pelo menos dois cortes, e, consequentemente, nas de açúcar. Adicionalmente, protege o solo contra a erosão e evita a multiplicação de plantas espontâneas (Ambrosano et al., 2011).

Assim, no Estado de São Paulo, o sistema de produção de amendoim está vinculado à cultura da cana-de- açúcar. Porém, este sistema está bem consolidado em padrões de produção, pautados pela inovação, produtividade e qualidade do produto final.

A comercialização, a partir do produtor, é realizada por cooperativas, indústrias de óleo e farelo, beneficiadoras, indústrias de confeitos, empacotadoras, atacadistas e exportadoras (Freitas et al., 2005). Os produtos do sistema agroindustrial do amendoim compõem-se de amendoim em casca e descascado, óleo bruto e refinado, torta ou farelo e sementes para cultivo. Estes produtos são comercializados, tanto no mercado interno quanto no externo. Entretanto, as exportações de farelo e de sementes são pouco significantes (Martins \& Perez, 2006).

A produção é comercializada por meio de cooperativas ou, diretamente, ao cerealista (beneficiador), que avaliam a qualidade do produto (em relação à presença de aflatoxina e ao rendimento), fixam os preços e prazo de pagamento. $\mathrm{O}$ valor pago depende também da sazonalidade do mercado, seja para o consumo nacional, seja para a exportação (Santos et al., 2006).

Dos indicadores que estimam a rentabilidade de uma atividade econômica, o custo de produção é o susceptível de efetivo controle por parte do produtor. Após análise dos itens que o compõem, buscam-se alternativas com vistas a reduzi-lo, como a substituição de insumos onerosos por similares de valores mais baixos e semelhante eficiência; a mecanização de operações manuais, ou vice-versa; dependendo da dimensão do empreendimento e da tecnologia adotada (Castro et al., 2006).

O controle do custo de produção é fundamental, em função da estreita margem de rentabilidade da maioria das culturas. Assim, qualquer item pode contribuir significativamente para o custo final e, para o amendoim, essa situação não é diferente. Portanto, ao observar os itens dentro da receita, pode-se optar pela melhor alternativa no momento de aquisição de produtos ou escolha de determinado serviço.

Diante do exposto, este trabalho objetivou estimar o custo de produção e a rentabilidade do cultivo de amendoim cv. Runner IAC 886 , por meio de coeficientes técni$\cos$ de operações mecanizadas, insumos e mão de obra, relacionando-os com aspectos econômicos, na região de Jaboticabal, Estado de São Paulo.

\section{MATERIAL E MÉTODOS}

\section{Fonte de dados}

O cultivo do amendoim deu-se em área arrendada, de 12 ha, em solo do tipo Nitossolo Vermelho eutroférrico latossólico, textura argilosa (EMBRAPA, 2006), localizada no Município de Jaboticabal, Estado de São Paulo, a $575 \mathrm{~m}$ de altitude e com relevo caracterizado como suave ondulado. Sua localização geográfica é definida como: 
latitude $21^{\circ} 10^{\prime} 41^{\prime \prime}$ S e longitude $48^{\circ} 26^{\prime} 18^{\prime \prime}$ W. O clima é do tipo tropical com inverno seco, e classificado, de acordo como o Sistema Internacional de Classificação de Köppen, como Aw. A pluviometria média anual é de 1425 $\mathrm{mm}$, com concentração de chuvas no verão e seco no inverno. Não foi utilizada irrigação.

As operações desenvolvidas compreendem todo o ciclo da cultura, ou seja, a instalação, a condução da cultura, a colheita e o transporte até a unidade beneficiadora, que recebe a produção.

\section{Caracterização do sistema de produção}

O cultivar utilizado, Runner IAC 886, de porte rasteiro (tipo Virginia), o mais utilizado na região, apresentou ciclo de 130 dias, semeado no período das águas, 25 de novembro de 2010. O preparo da área foi realizado de maneira convencional, com uma subsolagem, uma gradagem pesada e uma gradagem leve, para realização da semeadura. A colheita foi totalmente mecanizada, por meio de arrancamento/enleiramento das plantas e posterior recolhimento e trilha pela colhedora.

As sementes, tratadas com carbendazin+thiran (dose de $150 \mathrm{~g}$ do produto comercial por $1 \mathrm{~kg}$ de sementes), foram adquiridas junto à referida cooperativa. $\mathrm{O}$ cultivo foi realizado em sistema convencional, com calagem e adubação de plantio com fórmula 04-14-08 ( $\left.\mathrm{N}-\mathrm{P}_{2} \mathrm{O}_{5}-\mathrm{K}_{2} \mathrm{O}\right)$.

Durante a implantação da cultura, a área foi gradeada antes da semeadura e aplicaram-se herbicidas de pré-emergência para o controle de plantas daninhas. Ao longo do ciclo da cultura, foram realizadas sete pulverizações, alternando-se produtos inseticidas e fungicidas, com intervalo médio de 14 dias, dependendo do nível de infestação e para prevenir as principais pragas e doenças, como manchas causadas por cercosporioses (Cercospora arachidicola e Cercospora personatum).

A colheita foi realizada em duas etapas: a primeira, denominada de arranquio, caracterizou-se pela passagem de equipamento arrancador/invertedor, no momento em que a maioria das vagens atingiu a maturidade fisiológica (70\% das vagens com coloração característica). As plantas foram arrancadas e invertidas por este equipamento, formando leiras, as quais ficaram expostas ao sol, por período de quatro dias, para redução da umidade das vagens e grãos. Após esse período, realizou-se a segunda etapa, a colheita propriamente dita, caracterizada pelo recolhimento das leiras por máquina recolhedora, que trilha, separa, limpa e armazena as vagens no seu tanque graneleiro, as quais foram transferidas para caminhões, no próprio campo, e transportadas até a unidade beneficiadora.

\section{Estrutura do custo de produção}

Foi utilizada a estrutura do Custo Operacional Total (COT) de produção, proposta por Matsunaga et al. (1976), obtendo-se o Custo Operacional Efetivo (COE) e o Custo Operacional Total (COT). O COE constitui-se na soma das despesas diretas, como operações mecanizadas, operações manuais, material consumido e despesas com serviços de terceiros e empreitadas. O COT é obtido somandose ao valor do COE outras despesas e o valor do arrendamento.

Os valores unitários de cada item, referentes a janeiro de 2011, foram calculados da seguinte forma:

- Custo horário da máquina e de implementos (HM): foram considerados os gastos efetuados com combustível, mais valor estimado para reparos e manutenção, garagem e taxa de seguro. Para o cálculo do custo horário de implementos, considerou-se consumo de graxa e reparos. A depreciação foi calculada com base no método linear, considerando-se valor residual para o trator igual a $20 \%$ do valor novo, enquanto, para os implementos, o valor residual foi considerado zero, dados obtidos pela cooperativa da região;

- Para as despesas com operações manuais foi considerado o valor da diária na região de Jaboticabal;

- Os preços dos insumos utilizados na produção foram obtidos na região de Jaboticabal;

- Para outras despesas (Transporte Externo, Despesas Administrativas, de armazenagem, Assistência Técnica, CESSR, Juros de Custeio, Seguro do Capital Fixo e Remuneração Esperada sobre o Capital Fixo), considerou-se a taxa de $5 \%$ sobre o $\mathrm{COE}$;

- O arrendamento equivaleu a $20 \%$ da produção, valor corrente na região.

Para análise econômica da produção de amendoim, em áreas arrendadas para reforma de canavial, foram considerados o preço médio recebido pelo produtor na safra 2010/2011, o preço médio dos últimos quatro $\operatorname{anos}(2007,2008,2009$ e 2010) e o Preço Mínimo de Garantia do Governo Federal, vigente no período da safra 2010/2011.

Foram estimados os seguintes indicadores de lucratividade, conforme Martin et al., (1998): receita bruta (RB), sendo o produto da quantidade obtida (em sacas de $25 \mathrm{~kg}$ $\mathrm{ha}^{-1}$ ) pelo preço médio da saca do amendoim, recebido pelos produtores; o lucro operacional (LO), calculado pela diferença entre a RB e COT; e o ponto de equilíbrio, definido como o nível de produção (preço) mínimo que determinada atividade pode suportar sem incorrer em prejuízos. Seu cálculo foi baseado nos custos e no preço para determinado período.

\section{RESULTADOS E DISCUSSÃO}

O valor do Custo Operacional Total (COT) calculado foi de $\mathrm{R} \$ 3.563,07 \mathrm{ha}^{-1}$ (Tabela 1). O Custo Operacional 
Efetivo (COE), que representa o desembolso realizado pelo produtor, foi de $\mathrm{R} \$ 2.764,82$, representando $77,6 \%$ do total de custos. As despesas com material representaram 38,8\% do COT, operações mecanizadas $27,57 \%$, arrendamento da terra com $18,5 \%$ e operações manuais com $11,2 \%$.

Dentre os gastos com materiais, merecem destaque as despesas com sementes $(15,5 \%)$, que, por, geralmente, apresentarem baixo potencial fisiológico, ou seja, baixa germinação e vigor, requerem maior quantidade; e com defensivos $(12,1 \%)$ por ser, a cultura do amendoim, muito susceptível ao ataque de pragas e doenças.
As operações de colheita, que consistem no arranquio, recolhimento e transporte, ficaram em torno de $\mathrm{R} \$ 672,60$ ha $^{-1}$, representando 18,9\% do COT (Figura 1) e este foi o maior peso dentro do COT, pelo fato de a operação de arranquio exigir tratores de alta potência (a máquina arracandora/invertedora apresenta partes que trabalham abaixo do nível do solo). Outro fator oneroso para a operação de colheita foi o recolhimento. A atividade de duas máquinas incrementa o custo das operações de colheita. E por fim, após o carregamento dos caminhões, há o valor do frete para o transporte da carga até a unidade beneficiadora.

Tabela 1. Custo Operacional Total para um hectare na cultura do amendoim cv. Runner IAC 886 na região de Jaboticabal, SP, safra 2010/11

\begin{tabular}{|c|c|c|c|c|c|}
\hline Descrição & Especif. & $\mathbf{N}^{0}$ vezes & Qtd. & V. Unit. & Total $(\mathbf{R} \$)$ \\
\hline \multicolumn{6}{|l|}{ A - Operações mecanizadas } \\
\hline Gradagem niveladora leve & $\mathrm{HM}$ & 1,00 & 0,60 & 35,95 & 42,71 \\
\hline Gradagem intermediária & $\mathrm{HM}$ & 1,00 & 0,80 & 33,77 & 53,49 \\
\hline Pulverização foliar & $\mathrm{HM}$ & 7,00 & 0,33 & 21,82 & 99,80 \\
\hline Transporte água & $\mathrm{HM}$ & 7,00 & 0,02 & 21,91 & 6,07 \\
\hline Calagem & HM & 1,00 & 0,36 & 31,89 & 22,73 \\
\hline Adubação de cobertura & $\mathrm{HM}$ & 1,00 & 0,50 & 17,84 & 17,66 \\
\hline Plantadora & $\mathrm{HM}$ & 1,00 & 0,85 & 38,95 & 65,55 \\
\hline Transporte interno & $\mathrm{HM}$ & 1,00 & 0,04 & 22,03 & 1,74 \\
\hline Arranquio & & 1,00 & 1,00 & 200,00 & 200,00 \\
\hline Colheita & & 1,00 & 13,60 & 21,00 & 285,60 \\
\hline Transporte produção & & 1,00 & 1,10 & 170,00 & 187,00 \\
\hline Subtotal A & & & & & 982,36 \\
\hline \multicolumn{6}{|l|}{ B - Operações Manuais } \\
\hline Mão de Obra & HD & 10,00 & 1,00 & 40,00 & 400,00 \\
\hline Subtotal B & & & & & 400,00 \\
\hline \multicolumn{6}{|l|}{ C - Material } \\
\hline Semente & $\mathrm{kg}$ & 1,00 & 145,00 & 3,80 & 551,00 \\
\hline \multicolumn{6}{|l|}{ Fertilizantes } \\
\hline Calcário & $\mathrm{t}$ & 1,00 & 1,50 & 73,00 & 109,50 \\
\hline Gesso & $\mathrm{t}$ & 1,00 & 1,00 & 19,10 & 19,10 \\
\hline Adubo & $\mathrm{t}$ & 1,00 & 0,35 & 780,00 & 273,00 \\
\hline \multicolumn{6}{|l|}{ Herbicidas } \\
\hline trifluralina & 1 & 1,00 & 2,00 & 7,80 & 15,60 \\
\hline \multicolumn{6}{|l|}{ Fungicidas } \\
\hline triazol + estrobirullina & 1 & 3,00 & 0,60 & 71,00 & 127,80 \\
\hline chlorotalonil & 1 & 6,00 & 2,30 & 12,60 & 173,88 \\
\hline triazol (tebuconazole) & 1 & 2,00 & 0,50 & 21,80 & 21,80 \\
\hline \multicolumn{6}{|l|}{ Inseticidas } \\
\hline Piretroide (Lambdacyalotrina 150) & 1 & 1,00 & 0,03 & 198,00 & 5,94 \\
\hline Fisiológico (Profenofós+Lufenuron) & 1 & 2,00 & 0,15 & 59,60 & 17,88 \\
\hline Piretroide + Neonicotinoide & 1 & 3,00 & 0,20 & 111,60 & 66,96 \\
\hline Subtotal C & & & & & $1.382,46$ \\
\hline Custo operacional efetivo (COE) & & & & & $2.764,82$ \\
\hline Depreciação & & & & & 102,14 \\
\hline Outras despesas & & & & & 138,24 \\
\hline Arrendamento & & & & & 660,00 \\
\hline Custo operacional total (COT) & & & & & $3.665,21$ \\
\hline
\end{tabular}

Fonte: Dados da pesquisa.

Rev. Ceres, Viçosa, v. 61, n.4, p. 475-481, jul/ago, 2014 
O cultivo das variedades rasteiras, predominantes na região, permitiu a mecanização em todas as etapas do processo de colheita, o que não era possível quando se utilizavam cultivares de porte ereto, como é o caso do IAC Tatu ST, que vem perdendo espaço no cenário de renovação de canaviais da região de Jaboticabal. Na cultura do feijão, em algumas regiões, o arranquio é manual, utiliza trabalhadores como mão de obra, assim, apresenta menores custos referentes a operações de colheita, $18 \%$ do COE (Oliveira et al., 2010).

O valor do arrendamento da terra, $20 \%$ da produção, representa 33 sacas ha $^{-1}$, equivalendo a $\mathrm{R} \$ 660,00 \mathrm{ha}^{-1}$, sendo bem representativo, pois equivale a $18 \%$ do COT (Figura 1), exigindo maior atenção do produtor na hora de realizar contratos.

Diferentemente dos de outras regiões produtoras de amendoim, os grandes proprietários rurais da região de Jaboticabal arrendam suas terras a terceiros para o cultivo do amendoim na entressafra da cana-de-açúcar, caracterizando, dessa forma a situação local da produção de amendoim. Esta prática é relevante para o proprietário, que precisa reformar a cultura de cana-de-açúcar, e independentemente do transcorrer da lavoura, terá sua renda, pois é o arrendatário o responsável pelo cultivo, sendo que, caso não arrendasse, a terra ficaria ociosa. Já, para o arrendatário, o sucesso da cultura depende do bom desenvolvimento do amendoim, assim como dos preços, para obter retorno econômico. Se o proprietário da terra cultivasse o amendoim em suas próprias terras, deixaria de existir o custo do arrendamento e, dessa forma, poder-seia obter maior retorno econômico com a lavoura. Dados obtidos no IEA (2011) mostraram que o valor do arrendamento de áreas de reforma de canaviais, para produção de amendoim, variou, na região de Jaboticabal, de R \$ 413,22 a R\$595,04 ha- ${ }^{-1}$ em 2010.
O custo com sementes apresentou o terceiro maior valor dentro dos insumos, $\mathrm{R} \$ 551,00 \mathrm{ha}^{-1}$, correspondendo a 15,5\% do COT (Figura 1).

O elevado custo com os defensivos agrícolas justifica-se por ser a cultura de amendoim muito susceptível a pragas (Tripes sp.) e doenças (Cercospora spp.) e assim, exige-se elevada quantidade de aplicações. Os produtos triazol + estrobirulina $(\mathrm{R} \$ 127,80)$ e chlorotalonil $(\mathrm{R} \$ 173,88)$ foram os que mais oneraram o COT, no item defensivos $(12,1 \%)$, pela quantidade utilizada e pelo número de aplicações, em comparação com as demais aplicações exigidas pela cultura. Também, como verificado por Oliveira et al. (2010), o item inseticidas/fungicidas participou com 15,8\% no COE da cultura do feijoeiro.

Com relação aos indicadores econômicos, a grande variação, entre os preços por saca de amendoim, no mercado pode ser determinante para a atividade (Figura 2). A receita bruta alcançada foi suficiente para cobrir o custo operacional total, calculado para a cultura; no caso do PMG a receita bruta quase cobriu o COT (Tabela 2).

O lucro operacional (LO) foi de R $\$ 1.228,53 \mathrm{ha}^{-1}$, para o preço médio dos últimos quatro anos. Para o preço médio da última safra, o LO foi baixo: R\$36,93 ha-1 , e para o PMG, praticamente os custos empataram com a receita obtida (Tabela 2).

A produtividade obtida também foi suficiente para cobrir os custos, atingindo o ponto de equilíbrio para o COT igual a $4.480 \mathrm{~kg} \mathrm{ha}^{-1}\left(178 \mathrm{sc} \mathrm{ha}^{-1}\right)$, com o preço de venda de $\mathrm{R} \$ 20,00$ por saca. Considerando-se a produtividade média obtida de $4.500 \mathrm{~kg} \mathrm{ha}^{-1}\left(180 \mathrm{sc} \mathrm{ha}^{-1}\right)$, restam, em cada hectare produzido, duas sacas para cobrir despesas gerais da propriedade, de remuneração do empresário (autoatribuído), da terra e de outros gastos e riscos intrínsecos à atividade (Tabela 2).

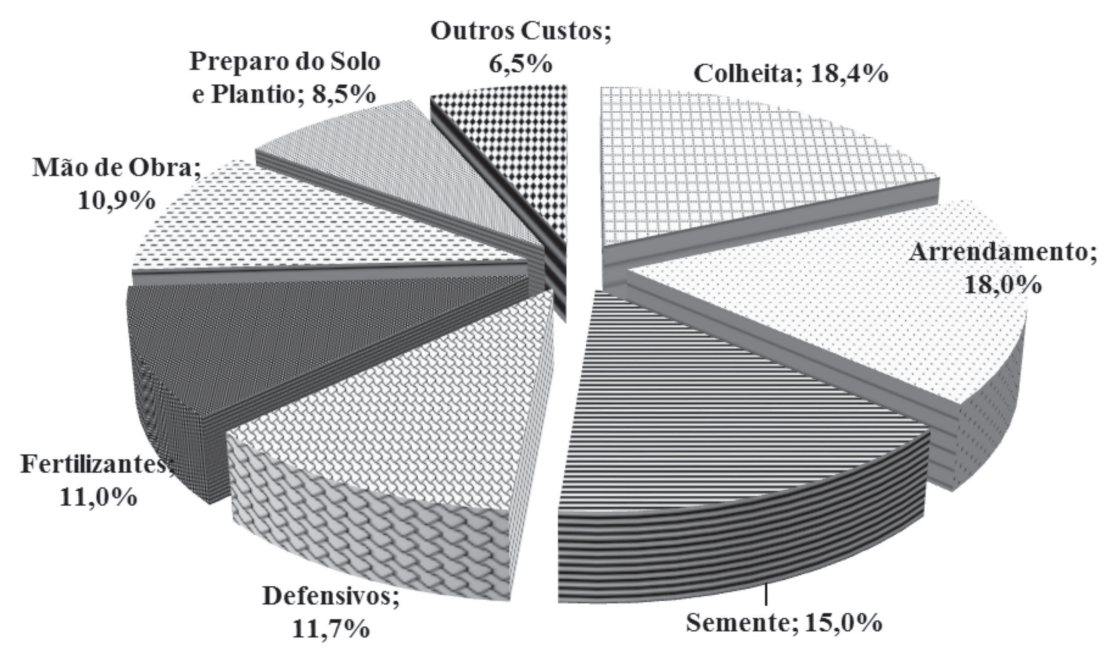

Figura 1. Participação percentual das operações e materiais no custo operacional total da cultura do amendoim, região de Jaboticabal, SP, Safra 2010/11. Fonte: Elaborada a partir dos dados da Tabela 1. 
O índice de lucratividade é um importante indicativo de rentabilidade, que mostra a proporção da Receita Bruta que se constitui em recursos disponíveis, após a cobertura dos custos operacionais totais, representado pela relação entre o LO e a RB em termos percentuais. No caso analisado, para se remunerar todos os custos calculados e obter rentabilidade positiva, deve-se ter preço de venda superior a $\mathrm{R} \$ 20,00 \mathrm{sc}^{-1}$, mostrando, mesmo assim, estreitas margens de remuneração. Deste modo, com o aumento da produtividade, maior poderá ser o índice de lucratividade, mas isso somente será concretizado se o valor da saca for superior ao ponto de equilíbrio em determinada safra.

A opção por cultivo de amendoim em áreas de reforma de canaviais mostrou bom resultado econômico, quando se consideraram os preços médios dos últimos anos, com lucratividade de 25,63\% (Tabela 2). Para o preço médio da última safra e Preço Mínimo de garantia (PMG), o resultado não foi satisfatório para os produtores.

No entanto, a cultura do amendoim é tradicional na região, sendo utilizada na reforma de canaviais, e agrega características agronômicas favoráveis à cultura da cana- de-açúcar, traz benefícios quanto à fertilidade do solo e à fitossanidade, proporcionando maior rendimento da cana, uma vez que, o solo ficaria em pousio por um período, sem a rotação de culturas. Dessa forma, o amendoim apresenta-se como uma opção economicamente viável, desde que o produtor já possua estrutura para implantação, condução e colheita, pois exige além de bom conhecimento técnico da cultura, maquinários especializados para o seu cultivo, além de a região apresentar condições climáticas favoráveis ao cultivo e cooperativas de recebimento, para beneficiamento e comercialização da produção.

Por essas razões, o conhecimento das técnicas de produção, juntamente com o do custo de produção permite o planejamento e gestão da propriedade e o sucesso da empresa em termos econômicos. Conhecer o custo de produção possibilita o planejamento orçamentário da atividade, realizado no início de cada ano agrícola. Um orçamento confiável permite prever qual o desembolso necessário ao longo da safra, e como poderá ser supervisionado o fluxo de caixa da atividade. Para Nogueira (2004), o produtor precisa produzir a um custo que lhe permita algum ganho.

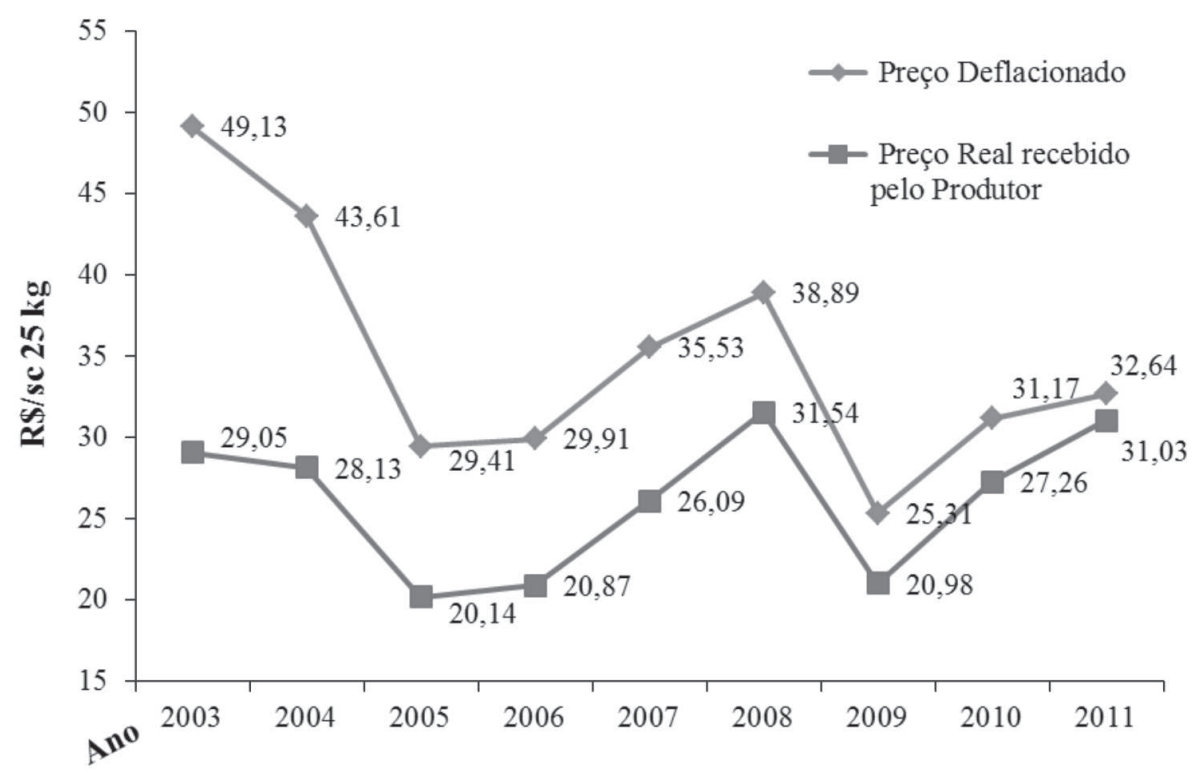

Figura 2. Preços médios anuais deflacionados e preços reais recebidos pelo produtor em $\mathrm{R} \$ / \mathrm{sc}$ de $25 \mathrm{~kg}$, segundo IGP-DI (FGV), do amendoim em casca para o Estado de São Paulo, no período de 2003 a 2011. Fonte: Agrianual (2013).

Tabela 2. Preços deflacionados, produtividade e indicadores de lucratividade do amendoim cv. Runner IAC 886, no município de Jaboticabal, 2011

\begin{tabular}{lrrr}
\hline Preço da saca de 25kg (R\$) & $32,64^{1}$ & $26,47^{2}$ & $18,33^{3}$ \\
\hline Produtividade (sc/ha) & 200,00 & 200,00 & 200,00 \\
Receita Bruta (R\$) & $6.528,00$ & $6.540,00$ & $3.666,00$ \\
\hline Lucro Operacional (R\$) & $2.862,79$ & $2.874,79$ & 0,79 \\
\hline Indice de Lucratividade (\%) & 43,85 & 43,96 & 0,20 \\
\hline 'Preço médio recebido pelo produtor; & & & \\
'2 Preço médio dos últimos 4 anos; & & & \\
'Preço Mínimo de Garantia. & & &
\end{tabular}

Rev. Ceres, Viçosa, v. 61, n.4, p. 475-481, jul/ago, 2014 


\section{CONCLUSÕES}

O custo operacional total da cultura de amendoim, na região de Jaboticabal, safra de 2010/2011, atingiu $\mathrm{R} \$$ $3.665,21 \mathrm{ha}^{-1}$. Este custo é considerado elevado, por causa, principalmente, das despesas com colheita e arrendamento da terra.

A produção de amendoim mostrou resultados econômicos satisfatórios para o preço médio pago ao produtor, no ano do levantamento, e para o preço médio de 2007 a 2010.

\section{REFERÊNCIAS}

Agrianual (2011) Anuário da Agricultura Brasileira. São Paulo, iFNP. Consultoria \& Comércio; $M$ \& S Mendes \& Scotoni. São Paulo, Editora Agors. 482p.

Agrianual (2013) Anuário da Agricultura Brasileira. São Paulo, iFNP. Consultoria \& Comércio; M \& S Mendes \& Scotoni. São Paulo, Editora Agors. 458p.

Ambrosano EJ, Cantarella H, Ambrosano GMB, Schammas EA, Dias FLF, Rossi F, Trivelin PCO, Muraoka T, Sachs RCC \& Azcón R (2011) Produtividade da cana-de-açúcar após o cultivo de leguminosas. Bragantia, 70:810-818.

Castro SH, Reis PR \& Lima ARL (2006) Custos de produção da soja cultivada sob sistema de plantio direto: estudos de multicasos no oeste da Bahia. Ciência e agrotecnologia, 30:1146-1153.

Conab (2012) Acompanhamento de safra brasileira: grãos, oitavo levantamento. Brasília. Disponível em: <http:// www.conab.gov.br/OlalaCMS/uploads/arquivos / 12_05_10_08_49_52_boletim_maio_2012.pdf>. Acessado em: 31 de maio de 2012.

Embrapa (2006) Centro Nacional de Pesquisa de Solos. Sistema Brasileiro de Classificação de Solos. Brasília. 412p.

Freitas SM, Martins SS, Nomi AK \& Campos AF (2005) Evolução do mercado brasileiro de amendoim. In: Santos RC (Ed.) O agronegócio do amendoim no Brasil. Campina Grande, Embrapa Algodão. p.15-44.

IEA Instituto de Economia Agrícola (2011a) Banco de dados: Terras - Valor do Arrendamento em Dinheiro. Disponível em: < h t t p : / / c i a gri.ie a.sp.gov.br/bancoie a / Precos_Medios.aspx?cod_sis=2>. Acessado em: 10 de agosto de 2011 .

IEA Instituto de Economia Agrícola (2011b): Preços Agrícolas. São Paulo: IEA, 2011. Disponível em: <http:// ciagri.iea.sp.gov.br/bancoiea/precos_medios.aspx?cod_sis=2>. Acessado em: 6 de novembro de 2011

Martin NB, Serra R, Oliveira MDM, Angelo JA \& Okawa H (1998) Sistema integrado de custos agropecuários - CUSTAGRI. Informações Econômicas, 28:7-28.

Martins R (2010) Amendoim: perspectivas para a safra paulista 2010/11. Análises e Indicadores do Agronegócio, 5:1-4.

Martins R \& Perez LH (2006) Amendoim: inovação tecnológica e substituição de importações, Brasil, 1996-2005. Informações econômicas, 36:07-19.

Matsunaga M, Bemelmans PF \& Toledo P (1976) Metodologia de custo de produção utilizado pelo IEA. Agricultura em São Paulo, 23:123-139.

Nakagawa J \& Rosolem CA (2011) O amendoim: tecnologia de produção. Botucatu, FEPAF. 325p.
Nogueira MP (2004) Gestão de custos e avaliação de resultados: agricultura e pecuária. Bebedouro, Scot Consultoria. 219p.

Oliveira MDM, Fachini C, Ramos Junior EU \& Ito MA (2010) Custo de Produção da Cultura do Feijão na Região Sudoeste Paulista. Análises e Indicadores do Agronegócio, 5:1-5.

Santos RC, Gondim TMS \& Freire RMM (2006) Mercado e comercialização. In: Suassuna TMF (Ed.) Cultivo de amendoim. Disponível em: <http://sistemasdeproducao.cnptia.embrapa.br/ FontesHTML/Amendoim/ CultivodoAmendoim/ mercado.html>. Acessado em: 20 de agosto de 2011. 